\title{
Furfural production from the peels of ripe english mango (mangnifera indica) fruits by acid catalyzed hydrolysis
}

\author{
D. Wankasi, ${ }^{1}$ T. J. Tarawou ${ }^{1}$ and E. P. Berezi ${ }^{2}$ \\ ${ }^{1}$ Department of Chemical Sciences, Faculty of Science, Niger Delta University, \\ Wilberforce Island, P.M.B. 071, Yenagoa, Bayelsa State, Nigeria. \\ Email: wankasi@yahoo.com \\ ${ }^{2}$ Department of Chemistry, Bayelsa State College of Education, Sagbama, P.M.B.74, \\ Yenagoa, Bayelsa State, Nigeria. \\ Email: sirepberezi@yahoo.com
}

\begin{abstract}
The peels of ripe mango (mangnifera indica) fruits were hydrolyzed with $4.5 \mathrm{M}$ hydrochloric acid solution and distilled. The distillates were tested for furfural using volumetric, UV/visible and IR spectroscopic methods in addition to other physicochemical parameters. The UV/visible and IR scans and the other tests confirm the presence of furfural. The result also show good yield of furfural.
\end{abstract}

Keywords; Furfural, production, mangnifera indica, hydrolysis.

\section{INTRODUCTION}

The use of agricultural residues as renewable sources of chemicals is of interest from both economic and environmental view points. It converts unwanted, low-value agricultural residues to useful and high-value feedstocks for chemicals. These residues are readily available in large quantity for use everywhere.

The importance of furfural and its derivatives has increased due to its very wide applications and this has made it imperative for the search for cheap, renewable and always available feedstock for the production of furfural.

Some of the applications of furfural and its derivatives include industrial chemicals and resins, solvent in petroleum industry, medicine, pesticides, antiseptics, disinfectors, insecticides, rust removers, and bio-fuels (De-jong and Marcotullio 2010)
The possibility of using agricultural by-products for the production of furfural has been recognized for many years and over the last 60years a more considerable fund of information has been built up. These include the production of furfural from corn-corbs, rice hulls, bagasse (Odozi etal, 1985), Garbage (Win, 2005), raphia hookeri (Wankasi and Tarawou, 2011), pawpaw and pineapple peels (Wankasi etal, 2011) and Banana and plantain peels (Wankasi and Yabefa, 2011).

The low yield of furfural from straw and other materials makes it desirable to extract the aqueous furfural distillate after acid hydrolysis by a solvent heavier than water such as chloroform. Sometimes the distillate is treated with enough sodium hydroxide so that the mixture is left just faintly acid, and the furfural separated (Adams and Voorhees 2011).

Furfural can be produced by acid catalyzed hydrolysis of agricultural by-products containing hemi-cellulose or pentosan 


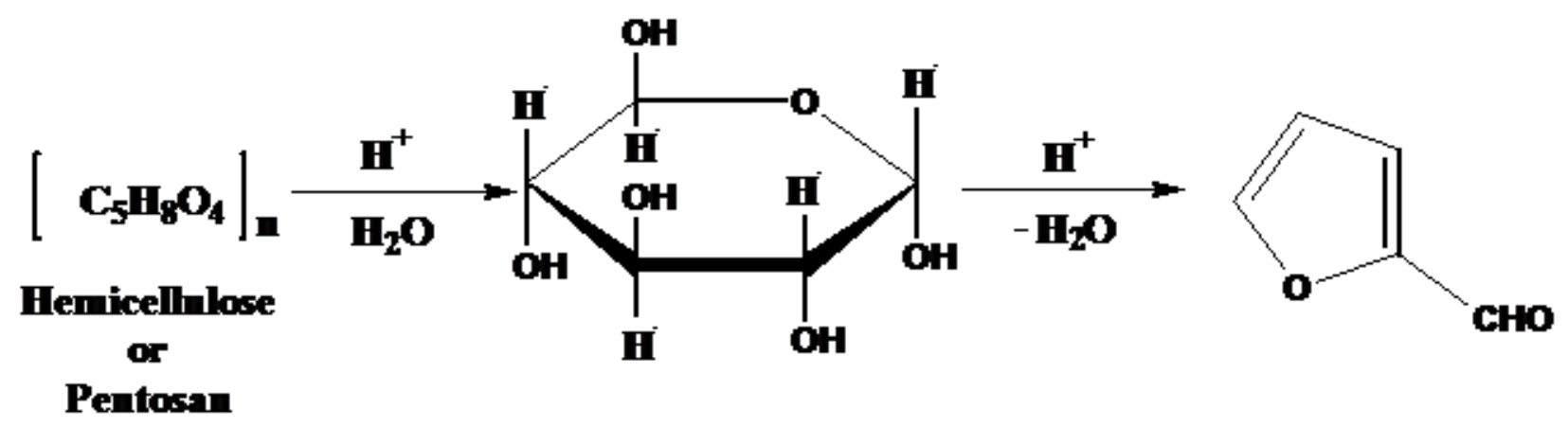

Pentosan is one of the important fibre component of the non-starch polysaccharides called hemicellulose. Hemi-cellulose can be any of several hetero-polymers present in almost all cell walls.

Mangnifera indica belongs to the family of Anarcadicacea lind. It is a dicotgenus of many species native to East Asia and Indomalaysia but now widely distributed in the tropical regions of the world. One of these species, mangnifera indicial is cultivated everywhere in Nigeria (Nyananyo 2006)

\section{MATERIALS AND METHODS}

Sample collection and preparation: Ripe mango (mangnifera indica) fruits were obtained from Swali market, Yenagoa in Bayelsa state of Nigeria. The peels of the fruit were separated from the edible mesocarp and chopped to reduce the sizes. The peels were then oven dried at $55^{\circ} \mathrm{C}$ for 48 hours and ground to 500 um mesh sizes.

Furfural production by acid hydrolysis: 25 grams of the 500um mesh sizes of the peels of ripe mangnifera indica were weighed into a round bottom flask and refluxed with $300 \mathrm{ml}$ of $4.5 \mathrm{HCl}$ solution for one hour. The hydroxylate was cooled and stored in brown reagent bottles for further experimentation.

Distillation of hydroxylate: $300 \mathrm{ml}$ of the hydroxylate were put into a round- bottomed flask in distillation unit set up with a receiver containing chloroform. The hydroxylate was then distilled so that the distillate (furfural) passed directly into the layer of chloroform contained in the receiver. Distillation was continued until there was no increase in the chloroform layer.

Distillation of furfural/ chloroform mixture (chloroform layer): $350 \mathrm{ml}$ of furfural/ chloroform mixture were put into a round- bottomed flask in a distillation unit. The flask was heated with an electrothermal heating mantle. The chloroform was recovered at $60^{\circ} \mathrm{C}$ while the furfural remained in the flask.

Density of distillate: The empty density bottle was weighed and recorded. The density bottle was then filled with the distillate and the weight recorded. The difference in weight was taken and the density computed.

Boiling point determination: $70 \mathrm{ml}$ of distillate was measured into a clean $100 \mathrm{ml}$ beaker and a thermometer with a capillary tube tied together was inserted. The beaker with its content was then heated using a hot plate until the first bubble was observed. The temperature at this point was read and recorded.

pH of distillate: The $\mathrm{pH}$ meter was standardized with buffer solutions and then $25 \mathrm{ml}$ of each sample distillate was measured into a beaker. The $\mathrm{pH}$ values were read and recorded when the meter readings were stable.

Furfural estimation in distillate $25 \mathrm{ml}$ of distillate was measured into a conical flask and $20 \mathrm{ml}$ of $0.05 \mathrm{M}$ potassium bromate/ bromide $\left(\mathrm{KBrO}_{3} / \mathrm{KBr}\right)$ solution added and allowed to stand for five minutes. $10 \mathrm{ml}$ of $5 \%(0.05 \mathrm{M})$ potassium iodide (KI) was then added and the liberated iodine titrated with a standard $0.1 \mathrm{M}$ sodium thiosulphate $\left(\mathrm{Na}_{2} \mathrm{~S}_{2} \mathrm{O}_{2} .5 \mathrm{H}_{2} \mathrm{O}\right)$ solution. Then the titre values (volumes of the $\mathrm{Na}_{2} \mathrm{~S}_{2} \mathrm{O}_{2} .5 \mathrm{H}_{2} \mathrm{O}$ ) were recorded. $\mathrm{A}$ blank experiment was conducted under the same conditions.

UV/Visible spectrophotometric scanning of distillates A Jenway 6505 single beam scanning spectrophotometer was used to scan the 
distillates. The equipment was set to scan from $200-700 \mathrm{~nm}$ at a scan speed of $5 \mathrm{~mm}$ per minute.

\section{IR Spectroscopic scanning of distillates:}

A drop of neat sample was placed between two polished flat sodium chloride plates (cells) which were squeezed together and mounted in the FTIR SPECTROPHOTOMETER (Model: Spectrum one- Perkin Elma) and scanned.

\section{RESULTS AND DISCUSSION}

Table 1 gives the density of the distillate as $1.15 \mathrm{~g} / \mathrm{ml}$ for the mangnifera indica fruit peels. This value is within the $1.16 \mathrm{~g} / \mathrm{ml}$ for furfural. This shows that the distillate was furfural.

Table1: Physicochemical properties and percent yield of distillate

Test mangnifera indica peels

$\mathrm{pH} \quad 5.73$

Boiling point $\left({ }^{\circ} \mathrm{C}\right) \quad 159$
Density $(\mathrm{g} / \mathrm{ml}) \quad 1.15$

Colour light brown

\%yield $\quad 31.56$

The boiling point as indicated in Table 1 is $159^{\circ} \mathrm{C}$. This value is within the $161.7^{\circ} \mathrm{C}$ for furfural and further confirms the conversion of the mangnifera indica fruit peels to furfural. The $\mathrm{pH}$ value of 5.73 for the distillate is acidic.Table1 also gives a fairly high percent yield of the furfural to be 31.56.

The carbonyl groups of saturated aldelydes and ketones give a weak absorption band in the ultraviolet region between $270-300 \mathrm{~nm}$. This band is shifted to longer wavelengths $(300-350 \mathrm{~nm})$ when the carbonyl group is conjugated with a double bond (Solomon, 1978).

As the degree of conjugation increases, the absorption will shift to longer wavelength. Generally, each additional double bond increases or gives rise to longer wavelength. Each additional conjugated double bond increases the wavelength of absorption band for about 300nm (Kamalu and Ogbome, 2008).

\section{Figure 1: UV/Visible scan of mangnifera indica fruit peel distillate}

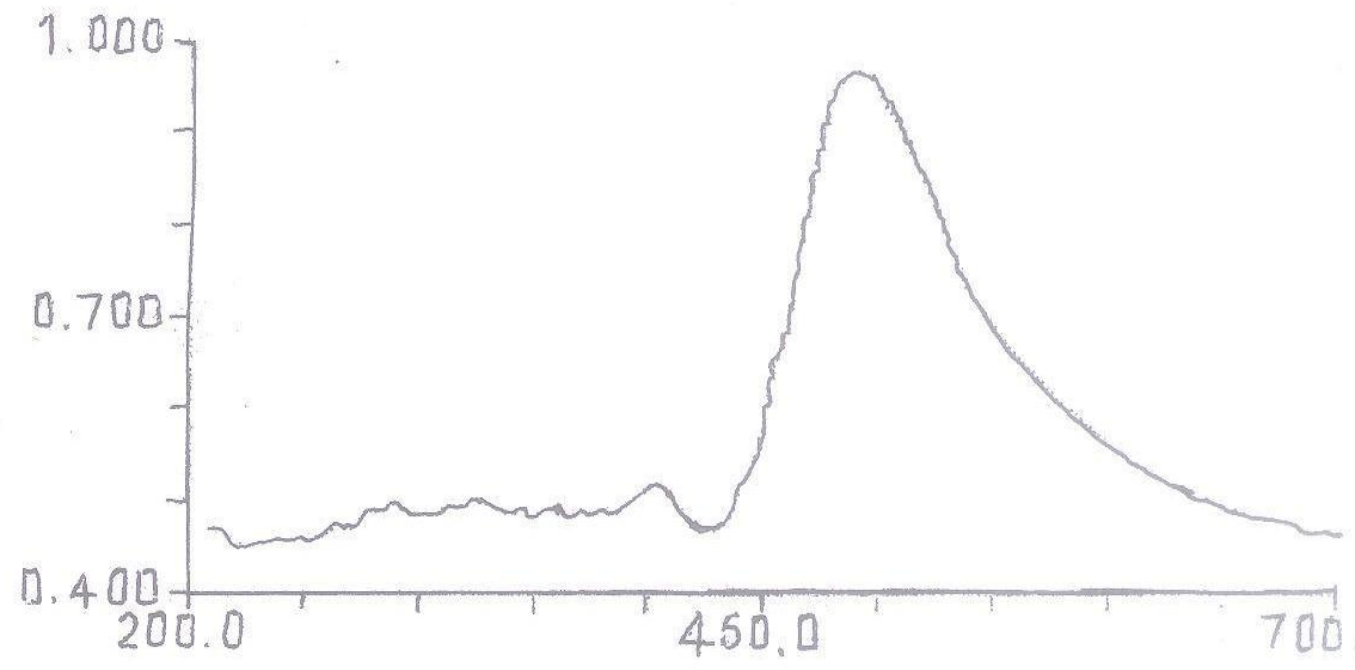


Examination of the resulting spectra as shown in figure 1 revealed broad absorption band in the region between $350-500 \mathrm{~nm}$ for the mangnifera indica fruit peel distillate. This significant absorption band indicate the presence of conjugated unsaturated bonds. This also further confirms the presence of furfural as the broad band may be due to the conjugation in the furfural.

Carbonyl groups of aldehydes and ketones give rise to very strong $\mathrm{C}=\mathrm{O}$ stretching bands in the $1665-1780 \mathrm{~cm}^{-1}$ region of the infrared spectrum.
The exact location of the peak depends on the structure of the aldehyde or ketone. For example $\mathrm{RCHO}(1729-1740 \mathrm{~cm}-1)$ Ar- $\mathrm{CHO}\left(1695-1715 \mathrm{~cm}^{-}\right.$ $\left.{ }^{1}\right),-\mathrm{C}=\mathrm{C}-\mathrm{CHO}\left(1680-1690 \mathrm{~cm}^{-1}\right)$. The $\mathrm{CHO}$ group of aldehydes also gives two weak bands in the $2700-2775 \mathrm{~cm}^{-1}$ and $2820-2900 \mathrm{~cm}^{-1}$ regions of the infrared spectrum (Solomon, 1978)

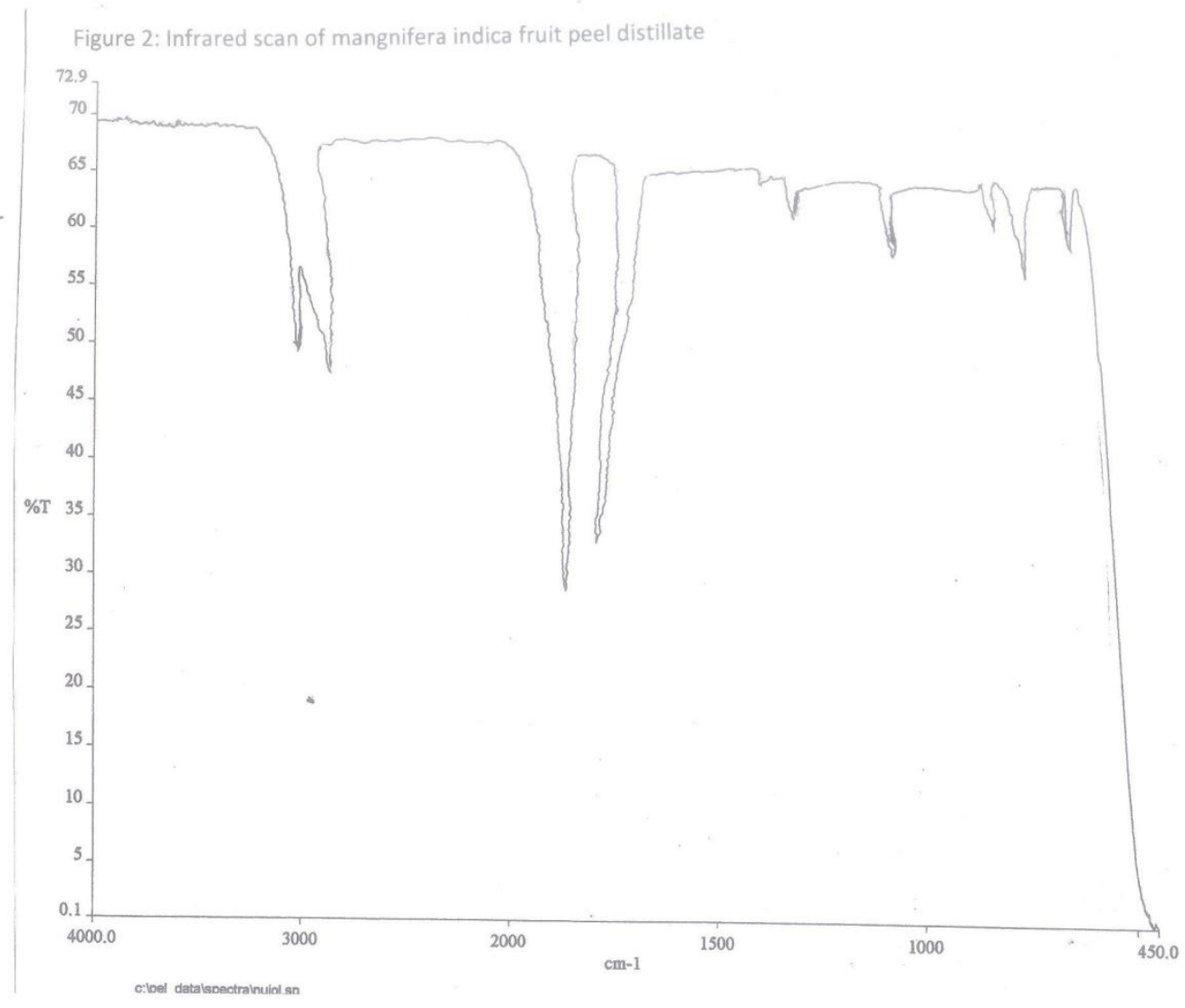

Figure 2 is the infrared spectrum of mangnifera indica fruit peel distillate. The spectrum shows sharp peaks between $1650-1700 \mathrm{~cm}^{-1}$ for the distillate which indicate the presence of aldelyde. This further confirms the production of furfural from the peels of mangnifera indica fruit by the acid catalyzed hydrolysis.

Conclusion: This study revealed a good yield of the furfural from the peels of ripe mangnifera indica fruits, which have been confirmed by the various tests including the Uv/visible and infrared spectrophotometric scans. Based on these findings, peels of ripe mangnifera indica fruits are good sources of renewable raw materials for the production of furfural. Furfural is a good source of chemicals and bio-fuels in the future bio-based economy.

\section{REFERENCES}

Adams R and Voorhees-checked by Clarke H. T. and Taylor E,R (2011); Organic synthesis, coll. Vol. 1 pp.49 and 280 (copyright). 
De- Jong W and Marcotullio G. (2010); Overview of Bio-refineries based on Co- Production of furfural, Existing Concepts and Novel Developments. International Journal of Chemical Reactor Engineering, Vol. 8, Article A69.

Kamalu O.I.C and Ogbome P. (2008); Extraction and Characterisation of Tiger Nut Oil J. chem. Soc. Nigeria, vol. 33, No. 1, pp 79-87.

Nyananyo, B.L (2006); Plants from the Niger Delta. Onyoma Research Pub. Pp. 24-303.

Odozi T.O, Akaranta O. Ogban I. U. (1985). Development of Wood Varnishes from Palm Fruit Fibre Hydroxylate (Eliesis Gelineesis) and Red Onion skin (Allium cepa) Tannin Extract. JOCCA 4:94-97

Saad S.M; Naser A.M; EL-Zi M, Abel-Moged (1978); 2Furfuraldehyde (furfural) formation from Local Byproducts and its Utilization in the Field of Surface Coatings. JOCCA 61:41-48
Solomon T.W.G. (1978). Organic Chemistry. John Whiley and Sons-New York. Chichelar. Barisbane. Toronto.

Win T.D (2005); Furfural from Garbage. AUJT. 8(4): $185-190$

Wankasi D and Yabafa J. A (2011), Furfural Production from the Peels of Ripe Banana (musa sapientum L) by Acid catalyzed Hydrolysis. Electronic Journal of Environmental, Agricultural and Food Chemistry (EJEAChe) 10(5) 2011 (2199-2205)

Wankasi, D and Tarawou T (2011). Furfural Production from Epicarp and Mesocarp of Raphia Hookeri Fruit by Acid catalyzed Hydrolysis. International Journal of Chemistry Vol. 21 No 2, 141-145

Wankasi D; Tarawou J.T and Yabefa A.J (2011). Furfural Production from the peels of Ripe Pawpaw (carica papaya) and Pineapple (ananas comosus) fruits by Acid catalyzed Hydrolysis. American Journal of Food and Nutrition. 1(3); 136-140. 